\title{
Relations between composition, digestibility and nutritive value of different feedstuffs in the rabbit
}

\author{
J. MARTINEZ PASCUAL, J. FERNANDEZ CARMONA \\ Cat. Alimentación Animal, E.T.S.I.A. Universidad Politecnica, \\ Avda. Blasco Ibañez, 2I. Valencia-Io (Spain)
}

\begin{abstract}
Digestibility coefficients, energy values and food intake of barley, sunflower oil meal, sugar beet pulp, dehydrated lucerne, lucerne hay, barley brewers grain, grape marc and olive oil meal were determined in adult New Zealand White Rabbits.

Metabolisable energy values were near $3.4 \mathrm{Mcal} / \mathrm{kg}$ for barley and beet pulp. The protein fraction of sunflower oil meal was highly digestible. Metabolisable energy values near 2.4 Mcal/ $\mathrm{kg}$ were found for barley brewers grain and dehydrated lucerne and its protein had a digestibility value of about $60 \mathrm{p}$. Ioo. Incerne hay had a low nutritive value. Grape marc and olive oil meal had no practical value as a feedingstuff (ME near $0.45 \mathrm{Mcal} / \mathrm{kg}$ ).

Statistical correlations and regression equations between digestibility coefficients and food composition were determined. ADF and ADL figures were found to be more valuable predictors than crude fibre and silica for digestibility and energy values. The effect of food intake on these parameters is discussed.
\end{abstract}

\section{The utilization of root flour of buffalo gourd (Cucurbita Fœtidissima, H.B.K.) for feeding rabbits in northern Mexico}

\author{
E. MORALES ZUNIGA \\ Escuela Superior de Zootecnia, Universidad \\ autonoma de Chihuahua, Apartodo postal $F 28$ \\ (Mexico)
}

The Buffalo Gourd, (Cucurbita foetidissima, H. B. K.), is a plant which has important characteristics in relation to the agricultural development of arid zones. This plant and its characteristics have been known in Northern Mexico far more than fifteen years. However, there is a scarcity of information on its cultivation and use.

The seeds of Cucurbita foetidissima, H. B. K., have high levels of good quality protein and oil, the root has a high starch content and the leaves are very rich in protein.

Because this plant is naturally abundant in some areas, it seems reasonable to consider its cultivation for animal feeding. Such cultivation should be relatively easy.

The purpose of this study was to evaluate the suitability of a flour made from the roots of Cucurbita foetidissima, H. B. K. as a substitute for sorghum in commercial rabbit feeds. New Zealand White Rabbits were fed on diets containing 0 , 10,20 and 30 p. 100 of root four made from this plant as substitute for sorghum.

There were no significant differences between the dietary treatments on gestation and lactation of New Zealand White females, or on the post weaning performance of their litters.

It was concluded that root flour from Cucurbita foetidissima, H.B.K., would be a useful and cheap ingredient in rabbit feeds. 